\title{
Desempenho agronômico de algodão orgânico e oleaginosas consorciados com palma forrageira
}

\author{
Gildivan dos S. Silva ${ }^{1}$, Rodolfo A. de Oliveira ${ }^{2}$, Nicholas L. Queiroz ${ }^{3}$, \\ Melchior N. B. da Silva ${ }^{4}$, Manoel F. de Sousa ${ }^{4}$ \& Sherly A. da Silva ${ }^{5}$
}

\begin{abstract}
RESUMO
Neste trabalho o objetivo foi avaliar o desempenho agronômico de algodão orgânico e oleaginosas consorciados com a palma forrageira no semiárido paraibano. No ano agrícola de 2009 foram conduzidos dois experimentos, em duas áreas: (I) na Fazenda Vila Maria Rita, situada no município de Taperoá, no cariri paraibano (II) no Assentamento Queimadas localizado em Remígio, no Curimataú paraibano enquanto os tratamentos, divididos em cultivo solteiro e consorciado, foram: algodão + gergelim + palma forrageira; algodão + amendoim + palma forrageira; algodão + palma forrageira; algodão solteiro; gergelim solteiro; girassol solteiro; amendoim solteiro e palma forrageira solteira. As variáveis analisadas foram: características tecnológicas de fibras, produtividade (grãos/caroço), rendimento em óleo, rendimento em fibra, renda bruta e uso eficiente da terra (UET) parcial e total. Para o rendimento em fibra o consórcio algodão + palma forrageira proporcionou o melhor resultado $\left(311,14 \mathrm{~kg} \mathrm{ha}^{-1}\right)$ enquanto o amendoim solteiro apresentou maior rendimento em grãos $\left(967,00 \mathrm{~kg} \mathrm{ha}^{-1}\right)$ e em óleo $\left(428,02 \mathrm{~kg} \mathrm{ha}^{-1}\right)$. O consórcio algodão + gergelim + palma forrageira pode ser uma alternativa eficiente na agricultura familiar uma vez que apresentou resultados positivos em termos de renda bruta e UET total.
\end{abstract}

Palavras-chave: consórcios, produção de óleo, agricultura familiar

\section{Agronomic performance of organic cotton and oilseed crops in combination with forage palm}

\begin{abstract}
The aim of this study was to evaluate the agronomic performance of organic cotton and oilseed crops in combination with forage palm in the semi-arid region of Paraiba, Brazil. In the 2009 crop year, an experiment was conducted in two areas: (I) at the farm Vila Maria Rita, located in the municipality of Taperoa in the 'Cariri' region of Paraiba, and (II) at the settlement of Queimadas, located in Remígio in the 'Curimatau' region of Paraiba. The treatments, separated into individual crop and in combination (intercropping), were: cotton + sesame + forage palm, cotton + peanut + forage palm; cotton + forage palm, cotton alone; sesame alone; sunflower alone; peanut alone, and forage palm alone. The variables analyzed were: technological characteristics of fibers, yield (seeds/boll), oil yield, fiber yield, gross income and efficient use of land (UET), partial and total. For fiber yield, the combination of cotton + forage palm provided the best result $\left(311.14 \mathrm{~kg} \mathrm{ha}^{-1}\right)$, while peanut alone had the greatest yield in seeds $\left(967.00 \mathrm{~kg} \mathrm{ha}^{-1}\right)$ and in oil $\left(428.02 \mathrm{~kg} \mathrm{ha}^{-1}\right)$. The combination of cotton + sesame + forage palm may be an efficient alternative for family agriculture since it showed positive results in terms of gross income and UET total.
\end{abstract}

Key words: intercropping, oil production, family agriculture

1 Pós-graduação em Agronomia - Solos e Nutrição de Plantas/UFC, Av. Mister Hull, 2977, CEP 60440-554, Fortaleza, CE. Fone: (85) 3366-9688 / 9927-9077. E-mail: gildivanldp@hotmail.com

2 Pós-Graduação em Agroecossistemas/UFSC, Rod. Admar Gonzaga, 1346, Itacorubi, CEP 80310-000, Florianópolis, SC. Fone: (48) $3721-5341$. E-mail: rodolfo.assis@posgrad.ufsc.br

${ }^{3}$ Programa de Pós-Graduação em Agronomia/UFPB, Rodovia PB 079,Km 12, C. P. 66, CEP 58397-000, Areia, PB. Fone: (83) 3362-2300. E-mail: nicholaslq@hotmail.com

${ }^{4}$ Embrapa Algodão, Rua Oswaldo Cruz, 1143, Centenário, C. P. 174, CEP 58428-095, Campina Grande, PB. Fone: (83) 3182-4300. E-mail: melchior.silva@embrapa.br; manoel-francisco.sousa@embrapa.br

${ }^{5}$ Programa de Pós-Graduação em Ciência do Solo/UFPB, Rodovia BR 079 - Km 12, CEP 58397-000, Areia, PB. Fone: (83) 3362-2300. E-mail: sherly.agro@hotmail.com 


\section{INTRODUÇÃO}

Um dos desafios propostos para as atuais gerações é promover o crescimento e o desenvolvimento econômico sem, no entanto, destruir o meio ambiente. Durante os últimos anos o homem se preocupou apenas em promover a industrialização para melhorar o padrão de vida da humanidade (Benedetti et al., 2006). Este padrão foi alcançado mas o meio ambiente pagou caro por isso.

Vários programas foram sugeridos na tentativa de se amenizar o problema; um exemplo disto é o Programa Nacional de Produção e Uso de Biocombustível (PNPB), definido como um projeto energético sustentável que visa à geração de emprego, renda, inclusão social e sustentabilidade ambiental, a partir de oleaginosas selecionadas em função da região (Pessoa et al., 2007).

O PNPB é alvo de questionamento entre produção de biomassa para o biodiesel e a produção de alimentos (Peres et al., 2005). Este debate é maior no âmbito da agricultura familiar já que, nos últimos anos, os biocombustíveis pautaram as discussões de políticas públicas de desenvolvimento rural para o semiárido brasileiro.

Apesar disto, é notório que esta região tem grande potencial para o cultivo de diversas plantas oleaginosas, dentre elas o amendoim, o algodão, o gergelim e o girassol (Severino et al., 2006) razão por que a inserção dessas culturas nos agroecossistemas dos agricultores familiares do semiárido parece ser um fator preponderante para o sucesso do Programa.

Uma das hipóteses para um possível fracasso dos programas de Biodiesel no semiárido tem sido a pouca interação entre o novo cultivo (oleaginosas) e os sistemas locais de cultivo (milho, feijão e palma forrageira) os quais, segundo Leff (2002), contribuem com a biodiversidade. Esta é de fundamental importância para a qualidade do agroecossistema (Almeida et al., 2009).

Os sistemas de produção da agricultura familiar do semiárido buscam a diversificação dos cultivos locais (consórcio de milho e feijão) principalmente com cultivos forrageiros adaptados às condições de sequeiro da região. A palma-forrageira, por apresentar elevada adaptabilidade, tem sido um recurso utilizado para amenizar as dificuldades alimentares dos animais nas secas prolongadas (Farias et al., 2000).

Neste contexto, a integração de oleaginosas aos sistemas locais da agricultura familiar por meio do consórcio com forrageiras (palma forrageira - Opuntiae sp. e Nopaleae), é a estratégia mais racional para tornar as culturas oleaginosas uma fonte adicional de renda complementando as atividades já existentes na propriedade.

O consórcio é uma das formas de se estudar agroecossitemas que se adequem às condições da agricultura familiar. Segundo Assis \& Romeiro (2002), a melhor forma de se fazer esse estudo é por meio da integração dos aspectos ecológicos, agronômicos e socioeconômicos na compreensão e avaliação do efeito das tecnologias sobre os sistemas agrícolas e a sociedade, como um todo.

A eficiência do consórcio depende diretamente do sistema de cultivo e das culturas envolvidas havendo a necessidade da complementação entre estas (Bezerra Neto et al., 2003).
Além desta relevância outros aspectos são considerados principalmente para agricultores familiares que procuram um sistema que preconize a redução dos riscos de perda, maior aproveitamento da sua propriedade e maior retorno econômico além de constituir alternativa altamente viável para aumentar a oferta de alimentos (Andrade et al., 2001).

Além de ser muito importante no manejo dos sistemas agroecológicos, o cultivo consorciado proporciona maior diversidade de nichos e recursos que estimulam a agrobiodiversidade. Além do mais, melhora a ciclagem de nutrientes e estimula os processos naturais de controle de pragas e doenças. Tais fatores são preponderantes na obtenção do selo orgânico e social (Silva et al., 2007).

Para atingir este objetivo têm sido propostas formas de estimar a produtividade e a eficiência agronômica dos consórcios. Vários índices são sugeridos neste sentido, a saber: Uso Eficiente da Terra (UET), índice de agressividade e de competitividade. O UET, por exemplo, permite estudar os rendimentos combinados dos sistemas consorciados (Bezerra Neto et al., 2007).

Em virtude da grande importância de inserir o agricultor familiar na cadeia produtiva do biodiesel, entende-se a significância de se estudar formas alternativas de melhorar sua participação neste processo. Com base nesses argumentos, insere-se este trabalho de consorciação de algodão e culturas oleaginosas com palma forrageira.

Portanto objetivou-se, com o trabalho, avaliar o desempenho agronômico dos cultivos de algodão orgânico e oleaginosas consorciados à palma forrageira no semiárido paraibano.

\section{Material e Métodos}

Este trabalho foi desenvolvido no ano agrícola de $2009 \mathrm{em}$ duas áreas experimentais: (I) na Fazenda Vila Maria Rita situada no município de Taperoá, no cariri paraibano, a $7^{\circ} 12^{\prime} 23^{\prime \prime} \mathrm{S}$ e $36^{\circ} 49^{\prime} 25^{\prime}$ 'W; (II) e no Assentamento Queimadas, localizado em Remígio, no Curimataú paraibano, a $08^{\circ} 01^{\prime} 46,5^{\prime \prime} \mathrm{S}$ e $34^{\circ}$ $57^{\prime} 28,7^{\prime \prime} \mathrm{W}$.

O clima é semiárido com temperatura média anual de $30{ }^{\circ} \mathrm{C}$ e precipitação média anual de $511,7 \mathrm{~mm}$ para Taperoá (AEASA, 2010). Já para Remígio o clima é quente e úmido, com temperatura média anual de $24,5^{\circ} \mathrm{C}$ e pluviosidade de 1000 $\mathrm{mm}$ anuais (Cavalcante et al., 2008).

Os ensaios foram conduzidos em delineamento inteiramente ao acaso (DIC), composto por quatro repetições e oito tratamentos envolvendo os agroecossistemas consorciados (algodão + gergelim + palma forrageira; algodão + amendoim + palma forrageira e algodão + palma forrageira) e solteiros (algodão; gergelim; girassol; amendoim e palma forrageira).

Os tratamentos foram arranjados da seguinte forma:

- Agroecossistema 1 (T1): Consórcio de algodão herbáceo, palma forrageira e gergelim:

A palma foi plantada no espaçamento de $3,0 \times 0,67 \mathrm{~m}$, ao qual se intercalaram duas fileiras de algodão herbáceo no espaçamento de $1,0 \times 0,25 \mathrm{~m}$; três fileiras de gergelim (10 plantas $\mathrm{m}^{-1}$ ) foram plantadas entre as fileiras de algodão 15 dias após o plantio da malvácea. 
A configuração dentro da área útil foi a seguinte: $3 \mathrm{GE}$ : 2AL : 1PA (3 fileiras de gergelim, para 2 de algodão, para 1 de palma forrageira).

- Agroecossistema 2 (T2): Consórcio de algodão herbáceo, palma forrageira e amendoim:

A palma foi plantada no espaçamento de $3,0 \times 0,67 \mathrm{~m}$ intercalando-se duas fileiras de algodão herbáceo no espaçamento de $1,0 \times 0,25 \mathrm{~m}$; três fileiras de amendoim ( 7 plantas $\mathrm{m}^{-1}$ ) foram plantadas entre as fileiras do algodão.

A configuração dentro da área útil foi a seguinte: $3 \mathrm{AM}$ : 2AL : 1PA (3 fileiras de amendoim para 2 de algodão, para 1 de palma forrageira).

- Agroecossistema 3 (T3): Consórcio de algodão herbáceo, girassol e palma forrageira:

A palma foi plantada no espaçamento de $3,0 \times 0,67 \mathrm{~m}$, onde se intercalaram duas fileiras de algodão herbáceo no espaçamento de 1,0 × $0,25 \mathrm{~m}$; a palma foi plantada cinco meses antes da implantação do ensaio permanecendo no local até o final do experimento.

A configuração na área útil foi a seguinte: $2 \mathrm{AL}: 1 \mathrm{PA}$ ( 2 de algodão, para 1 de palma forrageira).

Duas fileiras de girassol foram plantadas entre cada parcela do consórcio atuando como barreira vegetada, no espaçamento de $1,0 \times 0,20 \mathrm{~m}$; todas as parcelas do plantio consorciado tiveram área de $42 \mathrm{~m}^{2}$ enquanto as parcelas do cultivo solteiro tiveram área de $25 \mathrm{~m}^{2}$ com exceção da palma solteira, em que a área de suas parcelas foi de $20 \mathrm{~m}^{2}$.

- Agroecossistema 4 (T4) - Algodão solteiro, com espaçamento de $1,0 \times 0,25 \mathrm{~m}$.

- Agroecossistema 5 (T5) - Gergelim solteiro, com espaçamento de $1,0 \times 0,10 \mathrm{~m}$.

- Agroecossistema 6 (T6) - Girassol solteiro, com espaçamento de $1,0 \times 0,20 \mathrm{~m}$.

- Agroecossistema 7 (T7) - Amendoim solteiro, com espaçamento de $1,0 \times 0,15 \mathrm{~m}$.

- Agroecossistema 8 (T8) - Palma forrageira solteira, com espaçamento de $1,0 \times 0,67 \mathrm{~m}$.

$\mathrm{O}$ experimento foi conduzido com base em sistemas de cultivo orgânico, dentro de uma proposta agroecológica. O preparo do terreno e o controle de ervas espontâneas foram realizados manualmente, com auxílio de enxadas e roçadeiras mecânicas. Essas também foram controladas com produtos alternativos, conforme Silva et al. (2007).

No controle de pragas e doenças lançou-se mão de folhas de nim indiano (Azadiracta indica A. Juss), folhas de maniçoba (Manihot glaziovii Muell. Arg.) e uma solução de manipueira produzida a partir da mandioca (Manihot esculenta Crantz).

Nos agroecossistemas foram escolhidas as seguintes variedades: amendoim (Arachis hipogaea L. cv. BR.1), algodão herbáceo (Gossypium hirsutum L. cv. BRS. Aroeira), gergelim (Sesamum indicum L. cv. Seda), palma forrageira (Opuntia ficus indica (L.) P. Mill - cv, Gigante) e variedade local de girassol (Helianthus annuus L.). As variedades foram utilizadas nos cultivos consorciados e solteiros.

A semeadura foi feita a partir de sulcos, com algodão e girassol semeados em 14 de março e gergelim e amendoim 14 dias depois. O desbaste ocorreu 30 dias após a semeadura (DAS). Foram feitas duas colheitas: (i) aos 137 DAS, colhendo- se algodão em rama, gergelim e amendoim; (ii) aos 142 DAS, colhendo apenas algodão e gergelim.

Em cada parcela foram coletadas amostras de solo na profundidade de 0 a $20 \mathrm{~cm}$, para análise química. As amostras foram acondicionadas em sacos plásticos transparentes devidamente identificados e conduzidas ao Laboratório de Fertilidade do Solo da Embrapa Algodão.

Os solos de ambas as áreas foram secados ao ar, destorroados e passados em uma peneira de $2 \mathrm{~mm}$ e caracterizados como Neossolo Flúvico para a área I e como Neossolo Regolítico para a área II (EMBRAPA, 2009). A Tabela 1 mostra os valores médios resultantes das análises de solo.

Tabela 1. Valores médios das características químicas do solo das áreas experimentais

\begin{tabular}{|c|c|c|c|}
\hline \multirow{2}{*}{ Características } & \multirow{2}{*}{ Unidade } & \multicolumn{2}{|c|}{ Áreas experimentais } \\
\hline & & Taperoá (I) & Remígio (II) \\
\hline pH em água $(1: 2,5)$ & - & 6,3 & 7,0 \\
\hline $\mathrm{Ca}^{+2}$ & $\mathrm{mmol}_{\mathrm{c}} \mathrm{dm}^{-3}$ & 39,0 & 45,9 \\
\hline $\mathrm{Mg}^{+2}$ & $\mathrm{mmol}_{\mathrm{c}} \mathrm{dm}^{-3}$ & 20,8 & 17,0 \\
\hline $\mathrm{Na}^{+}$ & $\mathrm{mmol}_{\mathrm{c}} \mathrm{dm}^{-3}$ & 0,6 & 0,4 \\
\hline $\mathrm{K}^{+}$ & $\mathrm{mmol}_{\mathrm{c}} \mathrm{dm}^{-3}$ & 4,2 & 5,8 \\
\hline$S$ & $\mathrm{mmol}_{\mathrm{c}} \mathrm{dm}^{-3}$ & 64,6 & 69,0 \\
\hline $\mathrm{H}+\mathrm{Al}$ & $\mathrm{mmol}_{\mathrm{c}} \mathrm{dm}^{-3}$ & 12,2 & 5,8 \\
\hline $\mathrm{T}$ & $\mathrm{mmol}_{\mathrm{c}} \mathrm{dm}^{-3}$ & 76,8 & 74,8 \\
\hline V & $\%$ & 85,0 & 92,0 \\
\hline $\mathrm{Al}^{+3}$ & $\mathrm{mmol}_{\mathrm{c}} \mathrm{dm}^{-3}$ & 1,3 & 0,3 \\
\hline$P$ & $\mathrm{mg} \mathrm{dm} \mathrm{m}^{-3}$ & 81,6 & 4,6 \\
\hline Matéria Orgânica & $\mathrm{g} \mathrm{kg}^{-1}$ & 10,0 & 15,5 \\
\hline
\end{tabular}

$\mathrm{Na}$ coleta dos dados escolheu-se uma área útil de $12 \mathrm{~m}^{2}$ nas parcelas em consórcios e $16 \mathrm{~m}^{2}$ para os solteiros estimando-se as produtividades em $\mathrm{kg} \mathrm{ha}^{-1}$. As variáveis analisadas no estudo foram: características tecnológicas de fibras e fio, rendimento em fibra, produtividade em grãos/caroço, rendimento em óleo, renda bruta e índice de uso eficiente da terra (UETs parcial e total).

Para determinação das características tecnológicas de fibras e fios coletaram-se 20 capulhos no terço médio superior da planta de algodão, nas parcelas, ainda em campo.

Todas as amostras foram pesadas e posteriormente analisadas no aparelho HVI (instrumento de alto volume) segundo metodologia proposta por Fonseca \& Santana (2002). Com isto, foram determinados: porcentagem de fibras $(\%$ FIBRAS); comprimento (UNH) em mm; uniformidade (UNF) em \%; resistência (STR) em gf tex ${ }^{-1}$; índice de fibras curtas $(\mathrm{SFI})$; alongamento à ruptura (ELG) em $\%$; índice micronaire (MIC); maturidade (MAT) em \%; reflectância (Rd) em \%; grau de amarelo $(+b)$ e índice de fiabilidade (CSP).

As sementes de algodão passaram, ainda, por uma separação da pluma para que se procedesse à análise apenas do material fibroso e se determinasse seu rendimento em fibra $\left(\mathrm{kg} \mathrm{ha}^{-1}\right)$; em seguida, foram deslintadas (retirada do línter) e conduzidas para a análise de óleo.

Após beneficiadas e secadas em estufa tipo BOD a uma temperatura de $65{ }^{\circ} \mathrm{C}$ por $72 \mathrm{~h}$, as sementes de algodão e das demais oleaginosas foram encaminhadas ao Laboratório Avançado de Tecnologia Química da Embrapa Algodão, para posterior análise. 
O teor de óleo foi determinado pelo método de Análise em Unicata com uso de um Sistema de Ressonância Magnética Nuclear de Baixo Campo (RMN). Os teores de óleo obtidos em percentagem foram estimados para rendimento de óleo $(\mathrm{kg}$ $\mathrm{ha}^{-1}$ ) em função do somatório das produtividades médias de cada cultura oleaginosa dentro de cada agroecossistema.

Para o cálculo da renda bruta utilizou-se a produtividade de cada cultura envolvida no agroecossistema em $\mathrm{kg} \mathrm{ha}^{-1}$, multiplicando-a pelo valor de venda local do produto individual de cada cultura em reais por quilo $\left(\mathrm{R} \$ \mathrm{~kg}^{-1}\right)$. O resultado dessa multiplicação gerou a renda bruta por cultura, em reais por hectare $\left(\mathrm{R} \$ \mathrm{ha}^{-1}\right)$. O somatório das rendas brutas por cultura resultou na renda bruta total por agroecossistema.

Em relação aos preços de venda foram considerados, para o algodão orgânico, $R \$ 6,00 \mathrm{~kg}^{-1}$ de pluma e $\mathrm{R} \$ 0,70 \mathrm{~kg}^{-1} \mathrm{de}$ caroço; para o gergelim, amendoim e girassol considerou-se um valor de $\mathrm{R} \$ 5,00 \mathrm{~kg}^{-1}$ e $\mathrm{R} \$ 4,00 \mathrm{~kg}^{-1}$ e $\mathrm{R} \$ 0,80 \mathrm{~kg}^{-1}$ de grãos, respectivamente e, para a palma forrageira fresca, o equivalente a $\$$ \$ $0,02 \mathrm{~kg}^{-1}$ (CONAB, 2011).

Para o cálculo do uso eficiente da terra (UET) de cada tratamento foi utilizada a Eq. 1 sugerida por Willey (1979) e Trenbath (1976):

$$
\mathrm{UET}=\frac{\mathrm{Yab}}{\mathrm{Yaa}}+\frac{\mathrm{Yba}}{\mathrm{Yaa}}
$$

sendo:

Yab - rendimento de algodão (a) em consórcio com a cultura consorte - amendoim, gergelim, palma forrageira (b)

Yaa - rendimento de algodão isolado

Yba - rendimento da cultura associada em regime de consórcio

Foram determinados UET Parcial e UET Total.

Os dados dos dois experimentos foram submetidos à Análise Conjunta e as médias comparadas pelo teste Tukey a 0,01 e a 0,05 de probabilidade.

\section{Resultados E Discussão}

Para produtividade em grãos/caroço, o agroecossistema amendoim solteiro diferiu apenas do algodão solteiro (Tabela 2). Para ambos os cultivos não houve diferença significativa a 0,01 e 0,05 de probabilidade quando comparados com os demais agroecossistemas; no entanto, o amendoim solteiro foi o que apresentou maior produtividade em grãos $\left(967,00 \mathrm{~kg} \mathrm{ha}^{-1}\right)$, diferente do algodão solteiro, que teve a menor produtividade em caroço $\left(423,40 \mathrm{~kg} \mathrm{ha}^{-1}\right)$.

O mesmo ocorreu com o rendimento em óleo, ou seja, apesar de o agroecossistema amendoim solteiro demonstrar valor superior $\left(428,02 \mathrm{~kg} \mathrm{ha}^{-1}\right)$ aos demais tratamentos, não houve diferença significativa a 0,01 e 0,05 de probabilidade entre os agroecossitemas avaliados, exceto entre os cultivos de algodão e girassol solteiros cujos rendimentos em óleo foram 104,00 e $115,00 \mathrm{~kg} \mathrm{ha}^{-1}$, respectivamente (Tabela 3).

Este resultado pode ser explicado pela baixa competição interespecífica principalmente por luz e nutrientes, fatores preponderantes que podem alterar o teor de óleo. Resultados
Tabela 2. Valores médios para produtividade em grãos e caroço $\left(\mathrm{kg} \mathrm{ha}^{-1}\right)$ e rendimento em óleo $\left(\mathrm{kg} \mathrm{ha}^{-1}\right)$ e rendimento em fibra $\left(\mathrm{kg} \mathrm{ha}^{-1}\right)$ em agroecossistemas agroecológicos

\begin{tabular}{|c|c|c|c|}
\hline Agroecossistemas & $\begin{array}{l}\text { Produtividade } \\
\text { grãos/caroço* } \\
\left(\mathrm{kg} \mathrm{ha}^{-1}\right)\end{array}$ & $\begin{array}{l}\text { Rendimento } \\
\text { em óleo** } \\
\left(\mathrm{kg} \mathrm{ha}^{-1}\right)\end{array}$ & $\begin{array}{l}\text { Rendimento } \\
\text { em fibra* } \\
\left(\mathrm{kg} \mathrm{ha}^{-1}\right)\end{array}$ \\
\hline $\begin{array}{l}\text { Algodão + } \\
\text { gergelim + palma } \\
\text { forrageira }\end{array}$ & $831,70 a b$ & $400,53 a$ & $183,00 \mathrm{a}$ \\
\hline $\begin{array}{l}\text { Algodão + } \\
\text { amendoim }+ \\
\text { palma forrageira }\end{array}$ & $909,80 a b$ & $263,01 a b$ & $241,15 \mathrm{a}$ \\
\hline $\begin{array}{l}\text { Algodão + palma } \\
\text { forrageira }\end{array}$ & $810,50 a b$ & $196,10 a b$ & $311,14 \mathrm{a}$ \\
\hline Algodão solteiro & $423,40 \mathrm{~b}$ & $104,00 \mathrm{~b}$ & $241,81 \mathrm{a}$ \\
\hline $\begin{array}{l}\text { Gergelim solteiro } \\
\text { Girassol solteiro }\end{array}$ & $\begin{array}{l}633,70 a b \\
466,80 a b\end{array}$ & $\begin{array}{l}371,03 \mathrm{a} \\
11500 \mathrm{~b}\end{array}$ & - \\
\hline Amendoim solteiro & $967,00 \mathrm{a}$ & $428,02 \mathrm{a}$ & - \\
\hline CV (\%) & 38,15 & 48,33 & 60,32 \\
\hline
\end{tabular}

* Médias seguidas da mesma letra não diferem entre si pelo teste de Tukey a 0,01 e a 0,05 de probabilidade

contrários a esses foram encontrados por Beltrão et al. (2010) em cujo trabalho o amendoim em consórcio com mamona apresentou maiores valores de rendimento em óleo em relação ao cultivo amendoim solteiro.

Em se tratando do rendimento de algodão em fibra, o agroecossistema algodão + palma forrageira mostrou-se superior em comparação aos demais (Tabela 2). Mesmo não havendo diferença significativa a 0,01 e a 0,05 de probabilidade entre os tratamentos, quando se consorciou a malvácea com a forrageira o rendimento foi considerado o maior $(311,14 \mathrm{~kg}$ ha ${ }^{-1}$ de fibra).

Esses resultados corroboram com o estudo de arranjos espaciais de consórcios intercalares entre milho e feijão que também demonstrou vantagens agronômicas e econômicas para os consórcios; os monocultivos precisariam de 18 a $67 \%$ a mais de área para se equipararem aos consórcios (Flesch, 2002); entretanto, deve-se considerar que as culturas do algodão e da palma forrageira são usadas na alimentação animal e agregam valor quando consorciadas.

Os cultivos consorciados também proporcionam estabilidade da produção em condições ambientais adversas, uso eficiente de recursos de crescimento limitado, diversidade biológica e potencial controle de pragas e doenças (Biabani, 2009) e podem ser a melhor estratégia em sistemas orgânicos onde o uso de fertilizantes minerais solúveis e de agrotóxicos não é permitido.

Na Tabela 3 observa-se que o consórcio algodão + palma forrageira deteve o maior valor de UET parcial $(2,27)$, porém não houve diferença significativa a 0,05 de probabilidade entre este agroecossitema e o consórcio algodão + amendoim + palma forrageira $(1,97)$. Nos dois consórcios o algodão deteve eficiência de 97 e $127 \%$, respectivamente.

Resultados semelhantes foram observados por Bezerra et al. (2007) quando consorciaram sorgo e milho em fileiras alternadas e o consórcio sempre se manteve em vantagem sobre o monocultivo embora os autores tenham percebido que quando o sorgo foi consorciado com o feijão de corda houve tendência de dominação da gramínea sobre a leguminosa, o 
Tabela 3. Valores médios de uso eficiente da terra (UET) parcial para cada cultura e total em agroecossistemas agroecológicos

\begin{tabular}{|c|c|c|c|}
\hline Agroecossistemas & $\begin{array}{l}\text { UET } \\
\text { Parcial }\end{array}$ & Agroecossistemas & $\begin{array}{l}\text { UET } \\
\text { Total }\end{array}$ \\
\hline \multicolumn{4}{|l|}{ Gergelim } \\
\hline $\begin{array}{l}\text { Algodão + gergelim + } \\
\text { palma forrageira }\end{array}$ & $1,01 \mathrm{~b}$ & $\begin{array}{l}\text { Algodão + gergelim + } \\
\text { palma forrageira }\end{array}$ & $2,58 \mathrm{a}$ \\
\hline \multicolumn{4}{|l|}{ Amendoim } \\
\hline $\begin{array}{l}\text { Algodão + amendoim } \\
+ \text { palma forrageira }\end{array}$ & $0,40 \mathrm{~b}$ & $\begin{array}{l}\text { Algodão + amendoim } \\
+ \text { palma forrageira }\end{array}$ & $2,99 \mathrm{a}$ \\
\hline \multicolumn{4}{|l|}{ Algodão } \\
\hline $\begin{array}{l}\text { Algodão + gergelim + } \\
\text { palma forrageira }\end{array}$ & $0,92 \mathrm{~b}$ & $\begin{array}{l}\text { Algodão + palma } \\
\text { forrageira }\end{array}$ & $2,83 a$ \\
\hline $\begin{array}{l}\text { Algodão + amendoim } \\
+ \text { palma forrageira }\end{array}$ & $1,97 \mathrm{a}$ & - & - \\
\hline $\begin{array}{l}\text { Algodão + palma } \\
\text { forrageira }\end{array}$ & $2,27 \mathrm{a}$ & - & - \\
\hline \multicolumn{4}{|l|}{ Palma Forrageira } \\
\hline $\begin{array}{l}\text { Algodão + gergelim + } \\
\text { palma forrageira }\end{array}$ & $0,65 \mathrm{~b}$ & - & - \\
\hline $\begin{array}{l}\text { Algodão + amendoim } \\
+ \text { palma forrageira }\end{array}$ & $0,62 \mathrm{~b}$ & - & - \\
\hline $\begin{array}{l}\text { Algodão + palma } \\
\text { forrageira }\end{array}$ & $0,56 \mathrm{~b}$ & - & - \\
\hline CV $(\%)$ & 51,89 & CV (\%) & 31,66 \\
\hline
\end{tabular}

Médias seguidas da mesma letra não diferem entre si pelo teste de Tukey a 0,01 e a 0,05 de probabilidade

que pode explicar o fato de a cultura do amendoim apresentar UET parcial menor que a do algodão no consórcio algodão + amendoim + palma forrageira uma vez que variedade de algodão testada (BRS Aroeira) teve dominância de porte em relação à leguminosa (BR1); já no consórcio do algodão + gergelim (BRS Seda) + palma forrageira não houve diferença neste aspecto.

$\mathrm{O}$ fato de a palma forrageira ter apresentado valores de UET inferiores a $1,0 \mathrm{em}$ todos os tratamentos, pode ser explicado pelo baixo índice de agressividade (competição) imposto sobre as demais culturas. Bezerra et al. (2007) evidenciaram que nas proporções de $50 \%$ de sorgo e $70 \%$ de milho, o rendimento do milho não foi afetado pelo sorgo.

Ainda neste contexto, avaliou-se o UET Total (Tabela 3) para determinar a eficiência dos agroecossistemas considerando-se o somatório médio das culturas dentro de cada consórcio e os comparando com as plantas em cultivo solteiro.

Todos os consórcios apresentaram vantagem sobre os monocultivos. Os consórcios algodão + gergelim + palma forrageira e algodão + palma forrageira, tiveram UET Total de 2,58 e 2,83, respectivamente e o consórcio algodão + amendoim + palma forrageira teve um índice de 2,99; isto se traduz numa eficiência de 158, 183 e $133 \%$, respectivamente, para os consórcios em relação aos cultivos solteiros (monocultivo). Bezerra et al. (2007) encontraram resultados semelhantes para UET Total no consórcio de sorgo + feijão de corda, em que o consórcio em cultivo alternado mostrou-se vantajoso sobre o monocultivo.

Tais resultados podem ser diferentes dependendo da cultivar envolvida no agroecossistema. Araújo et al. (2008) verificaram que o consórcio entre as cultivares BRS 201 de algodão e L7 de amendoim o UET se destacou em relação aos demais consórcios mas ainda permaneceu abaixo de 1,00, o que revelou a desvantagem do sistema consorciado em relação ao monocultivo.

O índice UET pode sofrer influência de fator temporal, como época de plantio, e espacial, como o espaçamento. Lima et al. (2008) constataram que o UET pode variar em função da época relativa de plantio das culturas. Já Bezerra et al. (2007) afirmaram que o índice UET pode ser influenciado quando se altera o arranjo populacional das culturas.

Considerando a renda bruta (Figura 1) verificou-se que o consórcio algodão + gergelim + palma forrageira apresentou o maior valor entre os tratamentos $\left(\mathrm{R} \$ 4.375,00 \mathrm{ha}^{-1}\right)$. Quando se consorciou o algodão + amendoim + palma forrageira, a renda bruta total decresceu $\left(\mathrm{R} \$ 3.178,00 \mathrm{ha}^{-1}\right)$, sendo menor que a encontrada no tratamento amendoim solteiro ( $\mathrm{R} \$$ 3.194,00 ha-1).

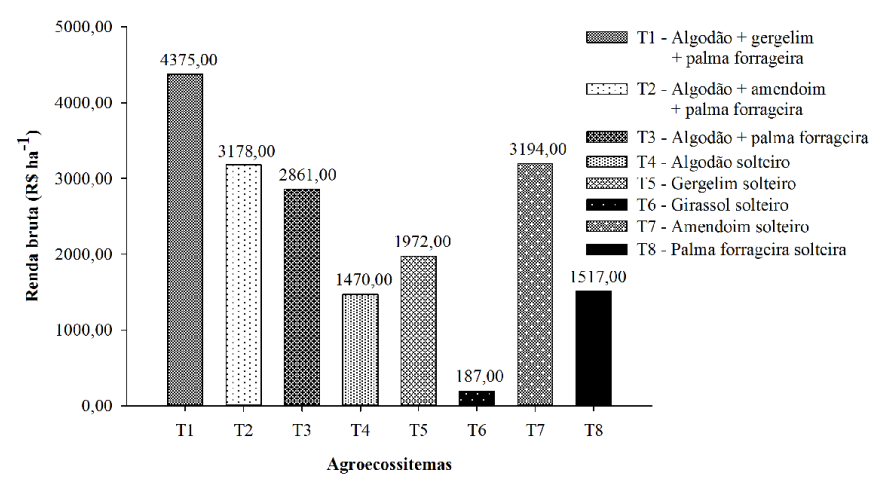

Figura 1. Renda bruta total distribuída nos agroecossistemas consorciados e solteiros

As plantas de algodão podem ter influenciado negativamente o desenvolvimento da leguminosa, a produção de grãos e a renda bruta. Araújo et al. (2006) conduziram um experimento com algodão associado ao amendoim e afirmaram que o sombreamento e a competição por água e outros recursos do meio foram, sem dúvida, os principais responsáveis pela queda na produção.

A palma forrageira solteira ofereceu renda bruta próxima à que foi proporcionada pelo algodão solteiro $\left(\mathrm{R} \$ 1.517,00 \mathrm{ha}^{-1}\right.$ e R $\$ 1.470,00 \mathrm{ha}^{-1}$, respectivamente). Esses resultados foram inferiores ao obtido com o consórcio algodão + palma forrageira ( R \$ 2.861,00 ha-1) e superiores ao obtido no cultivo girassol solteiro (R\$187,00 ha-1).

Apesar da renda se apresentar baixa quanto ao algodão e a palma forrageira, isto não impede o agricultor de usá-los na alimentação animal do seu rebanho uma vez que estará oferecendo fontes proteica e energética por meio da torta do algodão e girassol. Além disto, a palma forrageira supre a fome dos animais em longos períodos de seca.

Com relação às características tecnológicas de fibras e fios observou-se diferença significativa a 0,05 de probabilidade apenas para o grau de amarelo $(+b)$ em que o tratamento algodão solteiro demonstrou-se superior aos demais (Tabela 4). No entanto, as médias verificadas para a maioria das características do algodão estão nos padrões propostos pela indústria têxtil nacional e internacional (Fonseca \& Santana, 2002). 
Tabela 4. Valores médios* da porcentagem de fibras (\% FIBRAS), comprimento (UHM) em mm, uniformidade (UNF) em \%, resistência (STR) em gf tex ${ }^{-1}$, índice de fibras curtas (SFI), alongamento à ruptura (ELG) em \%, índice micronaire (MIC) em $\mu \mathrm{g} \mathrm{pol}^{-1}$, maturidade (MAT) em \%, reflectância (Rd) em \%, grau de Amarelo $(+b)$ e índice de fiabilidade (CSP) do algodão BRS Aroeira em agroecossistemas sob manejo agroecológico consorciado e solteiro

\begin{tabular}{lccccccccccc}
\hline Agroecossistemas & \% FIBRAS & UHM & UNF & SFI & STR & ELG & MIC & MAT & Rd & $\mathbf{+ b}^{*}$ & CSP \\
$\mathrm{Ag}+\mathrm{G}+\mathrm{PF}$ & $39,27 \mathrm{a}$ & $30,20 \mathrm{a}$ & $83,85 \mathrm{a}$ & $4,89 \mathrm{a}$ & $31,31 \mathrm{a}$ & $6,16 \mathrm{a}$ & $3,38 \mathrm{a}$ & $84,00 \mathrm{a}$ & $76,20 \mathrm{a}$ & $9,14 \mathrm{~b}$ & $3032,50 \mathrm{a}$ \\
$\mathrm{Ag}+\mathrm{Am}+\mathrm{PF}$ & $39,84 \mathrm{a}$ & $30,01 \mathrm{a}$ & $84,66 \mathrm{a}$ & $5,11 \mathrm{a}$ & $33,22 \mathrm{a}$ & $5,92 \mathrm{a}$ & $3,66 \mathrm{a}$ & $85,00 \mathrm{a}$ & $76,85 \mathrm{a}$ & $8,74 \mathrm{~b}$ & $3154,90 \mathrm{a}$ \\
$\mathrm{Ag}+\mathrm{PF}$ & $39,90 \mathrm{a}$ & $39,99 \mathrm{a}$ & $84,92 \mathrm{a}$ & $4,47 \mathrm{a}$ & $32,15 \mathrm{a}$ & $5,86 \mathrm{a}$ & $3,66 \mathrm{a}$ & $84,87 \mathrm{a}$ & $76,82 \mathrm{a}$ & $8,97 \mathrm{~b}$ & $3117,81 \mathrm{a}$ \\
Algodão solteiro & $38,99 \mathrm{a}$ & $29,82 \mathrm{a}$ & $84,07 \mathrm{a}$ & $4,89 \mathrm{a}$ & $33,87 \mathrm{a}$ & $5,59 \mathrm{a}$ & $3,66 \mathrm{a}$ & $85,04 \mathrm{a}$ & $75,20 \mathrm{a}$ & $10,09 \mathrm{a}$ & $3118,91 \mathrm{a}$ \\
CV (\%) & 3,39 & 1,69 & 0,93 & 25,60 & 9,61 & 9,61 & 10,21 & 1,16 & 3,22 & 7,51 & 6,01 \\
\hline
\end{tabular}

* Médias seguidas da mesma letra não diferem entre si pelo teste de Tukey a 0,01 e a 0,05 de probabilidade

\section{CONCLUSÕES}

1. As características tecnológicas de fibras se mostraram dentro dos padrões da indústria têxtil.

2. No rendimento em fibra o agroecossistema algodão + palma forrageira proporcionou melhor resultado; além disto, os consórcios ainda se destacam por proporcionar outros ganhos na renda do agricultor familiar.

3. Com relação ao rendimento em óleo, o amendoim solteiro proporcionou melhor resultado em relação aos demais agroecossistemas.

4. O consórcio algodão + gergelim + palma forrageira pode ser uma alternativa eficiente na agricultura familiar visto que apresentou resultados positivos de UET e renda bruta, parâmetros esses importantes na avaliação da eficiência do sistema.

\section{Agradecimentos}

À Embrapa Algodão, por ter cedido o espaço físico, e ao $\mathrm{CNPq}$, pela concessão da Bolsa e dos demais recursos financeiros capazes de facilitar a execução deste trabalho.

\section{Literatura Citada}

AEASA - Agência Executiva de Gestão das Águas do Estado da Paraíba. Monitoramento do período chuvoso (2010). $<$ http:// site2.aesa.pb.gov.br/aesa/monitoramento Pluviometria $>$. 06 Mar. 2011.

Almeida, M. V. R. de; Oliveira, T. S.; Bezerra, A. M. E. Biodiversidade em sistemas agroecológicos no município de Choró, CE, Brasil. Ciência Rural, v.39, p.1080-1087, 2009.

Andrade, M. J. B.; Morais, A. R.; Teixeira, I. R.; Silva, M. V. Avaliação de sistemas de consórcio de feijão com milho pipoca. Ciência e Agrotecnologia, v.25, p.242250, 2001.

Araújo, A. C.; Beltrão, N. E. de M.; Bruno, G. B.; Morais, M. dos S. Cultivares, épocas de plantio e componentes da produção no consórcio de algodão e amendoim. Revista Brasileira de Engenharia Agrícola e Ambiental, v.10, p.357363, 2006.

Araújo, A. C. de; Beltrão, N. E. de M.; Morais, M. dos S.; Araújo, J. de L. O.; Cunha, J. L. X. L.; Paixão, S. L. Indicadores agroeconômicos na avaliação do consórcio algodão herbáceo + amendoim. Ciência e Agrotecnologia, v.32, p.1467-1472, 2008.
Assis, R. L. de; Romeiro, A. R. Agroecologia e agricultura orgânica: controvérsias e tendências. Desenvolvimento e Meio Ambiente, v.6, p.67-80, 2002.

Beltrão, N. E. de M.; Vale, L. S. do; Marques, L. F.; Cardoso, G. D.; Souto, J. S. Consórcio mamona e amendoim: opção para a agricultura familiar. Revista Verde de Agroecologia e Desenvolvimento Sustentável, v.5, p.222-227, 2010.

Benedetti, O.; Plá, J. A.; Rathmann, R.; Padula, A. D. Uma proposta de modelo para avaliar a viabilidade do biodiesel no Brasil. Teoria e Evidência Econômica, v.14, p.81-107, 2006.

Bezerra, A. P. A.; Pitombeira, J. B.; Távora, F. J. A. F.; Vidal Neto, F. C. Rendimento, componentes da produção e uso eficiente da terra nos consórcios sorgo $\mathrm{x}$ feijão-de-corda $\mathrm{e}$ sorgo x milho. Revista Ciência Agronômica, v.38, p.104108, 2007.

Bezerra Neto, F.; Andrade, F. V.; Negreiros, M. Z.; Santos Júnior, J. J. Desempenho agroeconômico do consórcio cenoura $\mathrm{x}$ alface lisa em dois sistemas de cultivo em faixa. Horticultura Brasileira, v.21, p.635-641, 2003.

Bezerra Neto, F.; Gomes, E. G.; Nunes, G. H. S.; Oliveira, E. Q. Desempenho de sistemas consorciados de cenoura e alface avaliados através de métodos uni e multivariados. Horticultura Brasileira, v.25, p.500-506, 2007.

Biabani, A. Agronomic performance of intercropping wheat cultivars. Asian Journal of Soil Science, v.8, p.78-81, 2009.

Cavalcante, L. F.; Silva, M. N. B. da; Diniz, A. A.; Cavalcante, I. H. L.; Campos, V. B. Biomassa do maracujazeiro-amarelo em solo irrigado com água salina protegido contra as perdas hídricas. Revista Verde de Agroecologia e Desenvolvimento Sustentável, v.3, p.26-34, 2008.

CONAB - Companhia Nacional de Abastecimento. Acompanhamento de safra brasileira: grãos/ Quarto levantamento (safra 2010/2011). Brasília: CONAB, 2011. 41p.

EMBRAPA - Empresa Brasileira de Pesquisa Agropecuária. Centro Nacional de Pesquisa de Solos (Rio de Janeiro, RJ). Sistema brasileiro de classificação de solos. $2^{a}$.ed. Rio de Janeiro: Embrapa SPI, 2009. 412p.

Farias, I.; Lira, M. A.; Santos, D. C.; Tavares Filho, J. J.; Santos, M. V. F dos; Fernandes, A. P. M.; Santos, V. F. dos. Manejo de colheita e espaçamento da palma-forrageira em consórcio com sorgo granífero, no agreste pernambuco. Pesquisa Agropecuária Brasileira, v.35, p.341-347, 2000.

Flesch, R. D. Efeitos temporais e espaciais no consórcio intercalar de milho e feijão. Pesquisa Agropecuária Brasileira, v.37, p.51-56, 2002. 
Fonseca, R. G. da; Santana, J. C. F. de. Resultados de ensaio HVI e suas interpretações (ASTM D. 4605). Campina Grande: Embrapa CNPA, 2002. 13p.

Leff, E. Agroecologia e saber ambiental. Agroecologia e Desenvolvimento Rural Sustentável, v.3, p.36-51, 2002.

Lima, F. de S.; Beltrão, N. E. de M.; Oliveira, F. A. de; Pereira, W. E.; Sousa, C. da S. Épocas relativas de plantio e adubação nitrogenada: índices agroeconômicos do algodoeiro consorciado com gergelim. Revista Ciência Agronômica, v.39, p.555-561, 2008.

Peres, J. R. R.; Freitas Júnior, R. G.; Gazzoni, D. L. Biocombustíveis: Uma oportunidade para o agronegócio brasileiro. Revista de Política Agrícola, v.1, p.31-41, 2005.

Pessoa, V. M. N.; Souza, F. C. S.; Rebouças, I. G. O biodiesel como elemento de desenvolvimento sustentável no semiárido potiguar. Holos, v.3, p.113-125, 2007.
Severino, L. S.; Moraes, C. R. de A.; Gondim, T. M. de S.; Cardoso, G. D.; Beltrão, N. E. de M. Crescimento e produtividade da mamoneira influenciada por plantio em diferentes espaçamentos entre linhas. Revista Ciência Agronômica, v.37, p.50-54, 2006.

Silva, M. N. B.; Beltrão, N. E. de M.; Cardoso, G. D.; Santos, D. P.; Negreiros, K. V. Consórcio do algodoeiro colorido BRS 200 com feijão macassar sob manejo orgânico. Campina Grande: Embrapa Algodão, 2007. 21p. Boletim de Pesquisa e Desenvolvimento, 87.

Trenbath, B. R. Plant interactions in mixed crop communities. In: Papendick, R. I.; Sanchez, P. A.; Triplett, G. B. (ed.) Multiple cropping. Wisconsin: American Society of Agronomy, 1976. p.148-170.

Willey, R. W. Intercropping: its importance and research needs: Part 1. Competition and yield advantages. Field Crop Abstracts, v.32, p.1-10, 1979. 